\title{
Quando o campo é o estágio: etnografia e formação docente
}

\author{
FAGNER CARNIEL
}

UNIVERSIDADE ESTADUAL DE MARINGÁ (UEM), MARINGÁ/PR, BRASIL HTTPS://ORCID.ORG/0000-0002-7453-1993

\section{DANIARA THOMAZ}

UNIVERSIDADE FEDERAL DO PARANÁ (UFPR), CURITIBA/PR, BRASIL HTTPS://ORCID.ORG/0000-0001-6201-5230

\begin{abstract}
A academia não é o paraíso. Mas o aprendizado é um lugar onde o paraíso pode ser criado. A sala de aula, com todas as suas limitações, continua sendo um ambiente de possibilidades. Nesse campo de possibilidade temos a oportunidade de trabalhar pela liberdade, de exigir de nós e dos nossos camaradas uma abertura da mente e do coração que nos permita encarar a realidade ao mesmo tempo em que, coletivamente, imaginamos esquemas para cruzar fronteiras, para transgredir. Isso é educação como prática da liberdade.
\end{abstract}

bell hooks (2013:273)

\section{Apresentação}

Quem deseja cursar uma licenciatura e se habilitar ao exercício do magistério na Educação Básica brasileira já pode aguardar por uma prolongada imersão no cotidiano escolar. As reformulações curriculares nos cursos de formação docente têm ampliado sucessivamente o tempo de permanência nas escolas e as atividades práticas destinadas à atuação profissional nas diferentes etapas e modalidades de ensino. Em meio a tais mudanças, o estágio supervisionado assumiu um lugar estratégico na articulação entre os universos acadêmicos e escolares (Oliveira \& Barbosa, 2013). Idealizado para ser um espaço de aprendizagem, de experimentação e de identificação com a profissão (Araújo, 2019), é por meio do estágio obrigatório que estudantes das mais diversas áreas que compõem os currículos escolares acionam saberes especializados para desenvolver práticas, estabelecer relações e construir vivências em contextos reais de atuação pedagógica. 
Os estágios costumam iniciar-se pela própria "escolha” da instituição de ensino na qual o trabalho pedagógico será realizado. Nesse ambiente, estagiários e estagiárias experimentam pouco a pouco um processo de deslocamento e inadequação - já não são mais percebidos como discentes, mas também não podem assumir completamente a docência. Ao perceber-se em uma condição liminar, a expectativa é a de que a professoralidade se realize em todos e em cada como um tipo de "identidade profissional", que se caracteriza tanto pela prática sistemática de saberes relacionados ao magistério de sua disciplina, quanto pelo aprendizado de maneiras diversas de justificar sua atuação em sala de aula. Desse ponto de vista, a professoralidade pretendida para os estágios supervisionados estaria vinculada à compreensão daquilo que Tardif (2002) já denominou como "saber fazer" e "saber por que se faz".

No entanto, também é preciso considerar que tais processos de reconhecimento e de identificação com a profissão ultrapassam a mera apreensão intelectual de conteúdos curriculares e de práticas de ensino. Afinal, como argumentam Romaña e Gros (2003), trata-se de uma experiência que impacta a vida subjetiva e social de quem pretende assumir a posição de professor ou de professora e construir uma carreira na docência. Por isso mesmo, como observa Nóvoa (1992:4), é possível dizer que a profissão docente "transforma a pessoa do professor". Afinal, aprende-se com e através do corpo (Foucault, 1994). Aprende-se que o magistério tem cor, cheiros, formas, memórias, afetos, emoções, presenças (Estrela, 1997). Aprende-se a "educar a atenção" e a sensibilidade (Ingold, 2010). Desse modo, talvez não seja exagerado afirmar que, para se tornar docente, antes é preciso permitir-se ser afetado pelas experiências de estar na escola, em sala de aula, em relação a outros corpos e a tudo aquilo que envolve a prática pedagógica.

Definido o espaço, o tempo e as condições do estágio, cada área do conhecimento encaminha suas maneiras tradicionais de documentar da experiência vivida. Biografias, diários, entrevistas, mapeamentos, observações, relatórios. Na verdade, todas essas técnicas de reconhecimento e de compreensão dos sujeitos, bem como das realidades escolares, se organizam em torno das experiências e das relações que cada licenciando ou licencianda consegue tecer durante a sua formação. É através delas que o mundo escolar começa a ser (re)apreendido, adquire significados plurais e contraditórios, e os planos individuais ou coletivos de intervenção pedagógica passam a ser gestados. Trata-se, portanto, de um dos momentos mais sensíveis do processo de apercepção em relação ao magistério, tantas vezes descrito pela literatura pedagógica enquanto uma prática reflexiva que (trans)forma as trajetórias docentes (Passeggi \& Silva, 2010).

Em meio a tal percurso formativo, propomos a ideia de que a prática etnográfica pode contribuir com maneiras de educar a percepção de si e dos outros, por meio do aprofundamento de exercícios reflexivos de estranhamento e de desnaturalização que potencializam as experiências oferecidas ao longo dos estágios supervisionados em ciências sociais. A intenção não é sugerir que todas as pessoas devam se tornar antropólogas para assim se converterem em professoras, pois sabemos que nem sempre os compromissos científicos e pedagógicos convergem. No lugar disso, pretendemos argumentar que o contato com as perspectivas teóricas da antropologia e com o ofício etnográfico pode orientar a aprendizagem de novas maneiras de compreender o cotidiano escolar que, por sua vez, contribuirão para radicalizar o pensamento reflexivo e crítico na formação docente. 
Para isso, apresentaremos neste artigo os resultados de um exercício etnográfico realizado em uma instituição pública de ensino, localizada na região metropolitana da cidade de Maringá (PR). O objetivo é refletir sobre aspectos significativos da dimensão formacional da etnografia. O trabalho de campo baseia-se em uma experiência de estágio docente na disciplina de Sociologia, realizado ao longo do ano de 2018, com duas turmas de Ensino Médio.

A organização deste texto não procurou encobrir a habitual divisão de tarefas pela qual a formação docente costuma se estruturar: nas licenciaturas se estudaria o conteúdo, nos estágios, tal conteúdo seria praticado. Pelo contrário, procuramos explicitar essa assimetria inicial, por entender que as experiências em campo borram as fronteiras entre teoria e prática, o que pode nos ensinar como recompor aquilo que se faz nas universidades e nas escolas.

Desse modo, a intenção é argumentar que o trabalho etnográfico, enquanto um exercício pedagógico a ser realizado durante o estágio supervisionado, comporta o potencial de educar a percepção dos futuros professores e professoras a respeito da realidade escolar e de suas próprias condições de atuação nas instituições de ensino.

\section{Etnografia ou observação? A preparação para o estágio}

A etnografia, enquanto um fazer com tradição própria e articulada às diferentes perspectivas antropológicas, apresenta-se como possibilidade de compreensão do mundo e do humano que está aberta à captação da pessoalidade e do envolvimento de quem a realiza. Desse modo, a prática etnográfica não se fundamenta exclusivamente em ações metódicas, imparciais e desencarnadas. Pelo contrário, há relativo consenso antropológico na percepção de que o processo de produção do conhecimento etnográfico - muitas vezes representado pelos atos de "olhar, ouvir e escrever" (Oliveira, 1996) - depende, em grande medida, da própria assimilação da pessoa que pesquisa pelo campo pesquisado (Peirano, 2008).

Sua utilização instrumental na educação brasileira por não antropólogos, como "método" ou "técnica" de pesquisa, remonta à década de 1970. Naquele período, a "descoberta" da etnografia pela educação e a desvalorização da escola enquanto objeto de análise na antropologia acabaram levando à proliferação de tensões, desacordos e constrangimentos que marcaram a história recente de diálogos entre as áreas (Gusmão, 1997).

Após aproximadamente meio século de aproximações e distanciamentos, atualmente cultura e aprendizagem tornaram-se questões cruciais tanto para os projetos educacionais (Carniel, 2018), quanto para as pretensões antropológicas em intervir na formação humana (Rapchan \& Carniel, 2016). Nesse sentido, novas alianças parecem começar a esboçar um território “interdisciplinar”, que encontra no trabalho etnográfico uma maneira potencialmente significativa de estabelecer outros modos de habitar e de produzir o mundo (Pereira, 2017).

Tal aproximação, em que pesem as dificuldades institucionais e epistemológicas ainda presentes (Oliveira, 2017), apenas pôde reivindicar certa credibilidade acadêmica quando as etnografias produzidas em ambientes escolares conseguiram se afastar dos modos tradicionais de observação que individualizam e descontextualizam o fenômeno educacional (Fonseca, 1999), gerando conhecimentos 
atentos às diferenças e alteridades que nos constituem (e.g. Rocha, 2012; Carniel, 2013; Fians, 2015; Pereira, 2016; Pinho, 2018). O campo escolar, desse modo, deixa de ser encarado como um espaço isolado, no qual se "entra" e "sai" a fim de observar a formação humana, para emergir enquanto um lugar praticado, relacional, processual, por meio do qual nós mesmos enquanto pesquisadores(as) nos (trans)formamos enquanto pessoas.

Uma maneira de descrever esse tipo de experiência implicada no trabalho etnográfico que vem sendo amplamente empregada no discurso antropológico recente é através daquilo que Favret-Saada (1990) chamou de uma disposição ou preparação para "ser afetado" pelos múltiplos acontecimentos que ocorrem em campo. A expressão foi cunhada pela autora no contexto de uma etnografia da feitiçaria no Bocage francês, em 1968 e refere-se à experiência de estar em um "outro lugar", de ser acometido ou acometida por suas intensidades específicas, as quais não são imediatamente inteligíveis ou significáveis.

Trata-se, portanto, de algo que não conseguimos abarcar ou compreender por completo, mas que mesmo assim nos atravessa, que passa a nos habitar e nos modificar em nossas relações com e no mundo. Isso não quer dizer que nos tornaremos as pessoas com as quais estudamos. Não estaremos no lugar delas, não sentiremos, pensaremos ou agiremos como elas. Entretanto, compartilharemos o mesmo ambiente, experimentaremos eventos similares, ainda que a partir de condições sociais, profissionais e pessoais muito diferentes e seremos habitualmente convocados(as) a nos envolver em relações (etnográficas e pedagógicas) que carregam o potencial de gerar transformações recíprocas.

De acordo com Goldman (2003), essa concepção do trabalho etnográfico aponta para uma dimensão ética e existencial do ofício de pesquisa que já foi muito negligenciada pelas interpretações que oferecemos em nossos textos: o fato de que a experiência de pesquisa nos modifica, ou melhor, deveria nos modificar. Reconhecer a agência e a autonomia do campo em relação à rigidez de nossos pressupostos analíticos significa se mostrar capaz de compreender que o processo etnográfico não é construído de forma unilateral; ao contrário, a pesquisa se forma por meio das relações interdependentes que são estabelecidas em campo entre quem pesquisa e todo o universo pesquisado. Dessa forma, admitir a agência do campo significa se dispor a abrir espaço para a participação daqueles e daquelas que outrora foram denominados "objetos" de nossas pretensões de compreender o mundo.

O campo nos afeta, porque o "nativo" nos afeta. Consequentemente, afetamos juntos a pesquisa. Nessa perspectiva, como já observou Wagner (2010), o campo nada menos é do que um terceiro elemento na etnografia, que faz a junção entre a cultura do etnógrafo e aquela do nativo. E o faz tão bem que, em determinados momentos, questionamos: quem estuda quem? Por isso mesmo, trazer à tona as condições que promovem a escolha, a entrada e a familiarização com o campo por parte do(a) etnógrafo(a) é uma tarefa necessária para a tradição antropológica. Afinal, considera-se que, somente a partir das condições que possibilitam a nossa presença para o outro, começamos a percorrer os caminhos que nos habilitam a produzir conhecimentos, ao mesmo tempo verdadeiros e parciais, desinteressados e engajados, racionais e éticos, sobre as realidades que estudamos.

Assim, antes mesmo de definir o que será observado nas escolas, talvez os cursos de formação docente pudessem se inspirar na tradição etnográfica para incitar as pessoas a se perguntarem como estão sendo percebidas em campo e como essas múltiplas percepções constroem relações, afetos, ima- 
ginários, possibilidades, enfim... como nos educam como pessoas, mas também enquanto futuros professores e professoras.

\section{Estagiária-etnógrafa: aprendendo a compor com as diferenças}

No começo do segundo semestre de 2018, sob orientação do primeiro autor deste artigo, a segunda autora iniciou seu estágio supervisionado em Ciências Sociais no Colégio Estadual AML ${ }^{1}$, inclinada a produzir algum projeto que colocasse em diálogo os conceitos e as práticas antropológicas apreendidas por sua formação em andamento como cientista social e pela atuação enquanto estagiária, quase-professora. A partir desse ponto de vista, portanto, o artigo passa, por ora, a ser narrado na voz singular da discente.

A inclinação mencionada, certamente, estava associada ao fato de aquele mesmo colégio ter sido o local em que realizei o Ensino Fundamental e o Médio em anos anteriores, o que fez emergir algumas reflexões acerca de categorias clássicas da teoria antropológica, afinal, naquele contexto eu também era uma nativa. Retornar como estagiária ao colégio em que vivenciei a maior parte de minha formação educacional despertara, assim, algumas sensações e ideias ambíguas, que somente pude melhor entender quando imersa no processo de escrita daquilo que ouvia, sentia e via acontecer no entorno e sobre a escola (Ingold, 2016), ou ainda, quando imersa naquilo que Strathern (1987) concebeu como o "segundo campo" da pesquisa etnográfica.

A ambiguidade de tais sensações e ideias se dava, principalmente, por aquele único colégio apresentar diversos significados em minha trajetória pessoal: primeiro, enquanto local em que tive o contato inicial com as teorias e os conceitos que então respaldavam minhas análises e perspectivas sobre a sociedade em geral e sobre aquela escola em particular. Em seguida, ali também configurava o lugar no qual me vi e me viram pela primeira vez como professora, ou seja, o colégio que me formara como aluna agora me formaria professora também. Por fim, ainda ali, tive a experiência de conduzir este projeto de inspiração etnográfica, aguçando meus sentidos como pesquisadora e traçando uma relação mais intensa com a antropologia.

As seguintes partes desse texto podem ser definidas como um relato etnográfico, porém, mais que isso, as compreendo também como uma tentativa de condensar todas as informações que emergiram durante minha experiência de estágio-etnografia, a partir da posição ambígua de ex-aluna e estagiária-etnógrafa. Minha proposta é refletir sobre como a prática etnográfica e a literatura antropológica podem instrumentalizar a $(\mathrm{o})$ licencianda(o) para a experiência de um estágio supervisionado que consiga ir além da mera transmissão de conhecimento, potencializando a(o) estagiária(o) para compreender a realidade escolar e suas imbricações com a sociedade.

Parto, portanto, da perspectiva de Ingold (2016) sobre a antropologia como prática de educação, na qual a observação participante diz respeito menos à apreensão de dados objetivos que ao

1 Para respeitar as orientações sobre a conduta ética indicadas no termo de contrato do estágio supervisionado, alteramos o nome do colégio e suprimimos alguns detalhes das histórias narradas ao longo deste texto, com o objetivo de preservar a identidade das pessoas envolvidas. 
envolvimento e à disposição em ser transformado e educado por aquilo ou aquele(a) que se observa. Se, conforme Ingold afirmou, a observação participante e, consequentemente, a antropologia constitui formas de se viver "atencionalmente" com os outros, então, esse relato deve ser concebido como um compilado de acontecimentos, situações e sentimentos que vivenciei com atenção em meu campo-estágio e pelos quais também experimentei aspectos formativos de minha atuação como professora, cientista social e etnógrafa.

Fazia ao menos cinco anos desde a última vez que tinha cruzado o corredor de entrada da secretaria do Colégio AML e adentrado o pátio da escola, que se localiza no bairro em que nasci e fui criada, na região periférica da cidade de Maringá, no Paraná. Semanas antes, tinha ido ao colégio para negociar meu estágio supervisionado e assinar os termos de permissão com o diretor, meu antigo professor da disciplina de ciências no Ensino Fundamental. Contudo, nesse primeiro momento, minha presença não excedeu os limites da secretaria e da sala de direção, locais em que na minha época de aluna só eram acessados pelos estudantes em caso de problemas de saúde ou advertências pedagógicas, salvo poucas exceções.

Ao presenciar depoimentos de meus colegas de graduação sobre a dificuldade em encontrar uma escola e/ou um(a) professor(a) que aceitasse o estágio, compreendi que a minha negociação e entrada no Colégio AML foi facilitada pela condição de ex-aluna. Mais que eficácia e rapidez na resolução das documentações para o estágio, havia um tipo de interesse satisfatório, quiçá orgulhoso, por parte da escola, em receber uma antiga discente na posição de universitária e estagiária. Esses mesmos sentimentos também me beneficiaram em relação a diversas outras situações, desde a partilha de comidas e guloseimas que eram trocadas entre professores(as) até a inserção em reuniões e ocasiões restritas ao corpo docente e à parte administrativa do colégio, o que certamente colaborou para as observações e análises desse trabalho.

Nos primeiros dias, ainda sem definições para o projeto de inspiração etnográfica que planejava colocar em ação a partir de meu retorno à escola, limitei minhas atividades àquilo proposto no plano de estágio: análise do material didático disponível na biblioteca, observação da dinâmica e estrutura escolar, aproximação com o sistema on-line de controle de notas, faltas e presenças, etc. Tais ações, evidentemente, continuaram sendo realizadas mesmo após o início de meu projeto, o que mudaria, portanto, seria o olhar atribuído a esse (re)encontro com a escola, com as pessoas que ali estavam e o seu propósito.

Aproximando-me, dessa forma, da concepção de pesquisa antropológica sugerida por Ingold (2010,2016), compreendo que as características etnográficas desse projeto não se definiram exclusivamente pelo uso preciso dos métodos de pesquisa de campo ou mesmo pelo respaldo teórico que guiaram minhas ações e meus pontos de vista sobre o colégio, o estágio e minha presença ali. A caracterização desse projeto como etnográfico se deu, antes de qualquer coisa, pela minha intenção em "atender as pessoas e coisas, aprender com elas, e acompanhá-las em princípio e prática" (2016:408). Trata-se, assim, de um projeto que buscou na potência educativa e formativa da antropologia um espaço teórico e prático de diálogo para os conhecimentos pertinentes à disciplina de sociologia e os saberes acionados pelos alunos e alunas em sala de aula, por meio da experiência imersiva de estar e ser em campo. 
As minhas primeiras impressões, após uma breve caminhada de inspeção pelo colégio, eram as de que pouquíssimas coisas ou quase nada havia mudado. A estrutura física e o colegiado, as merendeiras e responsáveis pela limpeza, os livros e as bibliotecárias e até mesmo a estação de rádio em volume baixo, que contrariava as recomendações de silêncio na biblioteca, ainda eram as mesmas da minha época de aluna. Tão logo minha presença se tornou mais efetiva, entendi que, como estagiária de sociologia, precisaria ensinar aos alunos e alunas duas noções básicas da disciplina que, não por acaso, tinham se tornado o princípio fundamental de minha atuação e análise acerca do colégio que no passado me recebeu como estudante secundarista.

As noções de estranhamento e desnaturalização compreendem uma das funções base da disciplina de sociologia no Ensino Médio e para além dele: por meio delas, fenômenos corriqueiros e ordinários da sociedade se tornam passíveis de análise social e explicação científica. De acordo com as Orientações Curriculares para o Ensino Médio (2006: 107), tomar um acontecimento trivial e familiar como fenômeno social denota o processo de estranhamento dele, isto é, de retirá-lo do campo da naturalização - desnaturalizar e encará-lo com objeto de estudo, cujas causas externas e regularidade devem ser deslindadas e problematizadas pela sociologia.

Do mesmo modo, foi preciso estranhar não somente o local em si, mas também o olhar que lançava para aquele colégio, do qual as estruturas e a organização faziam parte da minha trajetória pessoal. Aquela familiaridade instigada pelas primeiras impressões e nutrida por experiências passadas não poderiam definir minha interpretação acerca do espaço físico e das relações que compunham o que agora denominava como campo. E, com efeito, não o fizeram.

Primeiro, por conta das mudanças na organização interna do colégio que, de fato, ocorreram, a despeito da imperceptibilidade desencadeada por um olhar inicial nostálgico. Segundo, ainda que nenhuma mudança houvesse ocorrido no interior do colégio, anos separavam a minha experiência como secundarista daquela enquanto estagiária-etnógrafa. Pressupor que minha perspectiva sobre a escola tivesse se mantido intacta desde minha adolescência seria, no mínimo, um ato de subestimação do bom trabalho realizado pelos professores e professoras durante meu curso de licenciatura.

Se minha perspectiva já não era a mesma, tampouco se mostrava igual minha consciência sobre as definições de escola, da relação ensino-aprendizado e das teorias sociológica e antropológica. Não se trata de invalidar as noções e ideias que tinha sobre tais questões e substituí-las por outras mais aprimoradas ou validadas cientificamente, mas sim de, como sinalizou Cheryl Rodriguez (2001) em sua argumentação sobre antropologia nativa, adquirir uma consciência múltipla que admita de modo concomitante nossas vivências e os conhecimentos da tradição antropológica.

Ainda assim, revelava-se necessária a elaboração de algum tipo de exercício que pudesse espessar essa consciência múltipla e, consequentemente, distinguir meus julgamentos pessoais das análises intersubjetivas, as quais realmente contribuiriam para uma compreensão antropológica sobre o colégio, as relações ali entretecidas e acerca do próprio projeto de inspiração etnográfica que buscava construir. Para isso, a escrita surgiu como melhor forma de produção daquilo que Strathern (1987) apontou como uma capacidade de maior reflexividade da antropologia feita em casa. Segundo ela, quando antropólogos e antropólogas se dispõem a estudar a sociedade da qual fazem parte, uma sensibilidade 
referente aos métodos e às ferramentas de análise é adquirida, tornando-os(as) suscetíveis a uma consciência mais ampla sobre suas posições como pesquisadores(as) e objetos de estudo.

$\mathrm{Na}$ atividade do estágio supervisionado, somos orientados(as) pelo supervisor(a) da disciplina a mantermos um caderno para anotações das dinâmicas na sala de aula, conteúdos pedagógicos e possíveis situações que nos despertem curiosidade ou interesse. Concomitante a isso, havia minha inclinação de produzir um projeto etnográfico. Desse modo, a escrita, ao menos nas primeiras semanas, foi recorrente durante meus períodos em sala de aula: escrevia para entender e desentender, para significar e ressignificar; algumas vezes, escrevia somente para transparecer que era uma pessoa estudiosa e, assim, tentar criar impressões positivas a respeito da seriedade do trabalho que estava realizando. De todo modo, a escrita configurou parte imprescindível de todo esse processo e foi a partir dela que compreendi, de fato, o meu propósito ao dar início a esse projeto de estágio-etnografia.

Ainda que minha entrada no colégio tivesse sido facilitada por ser ex-aluna, como qualquer pessoa que realiza o estágio supervisionado, também precisaria da autorização por parte da professora de sociologia, a quem chamarei de Lúcia, para acompanhá-la. Meu contato com Lúcia ocorrera por intermédio de um amigo em comum, o qual também me dera aula durante minha passagem como secundarista no colégio AML. Nossa primeira conversa, via rede social, foi extremamente objetiva: informei do meu interesse em estagiar no colégio e perguntei sobre sua disponibilidade em me receber. Em resposta positiva, Lúcia apenas me passou seus horários e disse me esperar na semana seguinte.

\section{A composição da diferença nas salas de aula}

Cientista social de formação e atuando como professora contratada temporariamente, Lúcia dividia seu tempo e conhecimento entre cinco turmas do Ensino Médio, sendo: duas do primeiro ano, outras duas do segundo e uma última do terceiro. Como muitos de seus pares, a professora também lecionava em turmas de outros três ou quatro colégios, às quais me convidou para conhecer depois de certa intimidade estabelecida entre nós. Em razão de outros compromissos da graduação, optei por acompanhá-la somente nas aulas das turmas do primeiro ano, denominadas neste texto como A e B, que contabilizavam quatro aulas por semana, divididas igualmente entre terça e quinta.

As opiniões de cunho negativo repercutidas entre professores e professoras sobre a turma A chegaram até mim antes mesmo do meu primeiro contato com os alunos e alunas da turma em questão. Nos primeiros dias, recebi diversos avisos por parte de docentes já antigos que diziam para me cuidar, pois a turma A "não quer nada com nada", ou então que sicrano ou fulano de turma A "me dariam trabalho". Durante os recreios, na sala dos professores, alguns estudantes desse primeiro ano eram figuras repetidas em discursos de desaprovação.

Em posição de ex-aluna, estava ciente do que poderia significar essas opiniões negativas, assim como entendia que as desaprovações eram direcionadas para alguns comportamentos específicos em sala de aula, como, por exemplo, conversas paralelas, uso de celulares e demais aparelhos eletrônicos e descumprimento das normas escolares gerais. Enquanto estagiária-etnógrafa, porém, evitava conformar essas opiniões, retomando o exercício de estranhamento e desnaturalização, ao reforçar a suposi- 
ção de que silêncio não é sinônimo de atenção ou interesse na/pela aula, assim como a ausência dele também não está intrinsecamente ligada ao desinteresse pelo conteúdo abordado, hipótese esta que pude confirmar durante minha atuação com este primeiro ano.

Com 35 alunos e alunas matriculados, as aulas na turma A eram marcadas por constantes pedidos de silêncio e interrupções de explicações para chamar atenção de estudantes por parte de Lúcia. Apesar disso, ou exatamente por isso, os conteúdos da disciplina pareciam surtir mais interesse entre os(as) discentes dessa turma. As teorias, os conceitos e as categorias sociológicas não passavam despercebidos, ao contrário: entre conversas aleatórias e triviais, causos do dia a dia e piadas, sempre havia alguma questão sobre o conteúdo trabalhado, com questionamentos direcionados principalmente a mim.

Importante dizer que o título de professora somente me foi atribuído pelos alunos(as) do primeiro ano A. Desde a primeira aula, ficara nítida a empolgação deles em relação a minha presença. Quando lhes era dada a opção de escolha sobre quem iria explicar o conteúdo, a resposta frequentemente se dava em minha preferência, o que nem sempre configurava interesse pela minha forma de lecionar; muitas vezes, percebia se tratar apenas de um teste para verificarem meu nível de compreensão acerca da matéria. De qualquer forma, havia um sentimento de curiosidade sobre aquela nova presença no cotidiano da sala de aula: as indagações sobre minha rotina na universidade e experiência como ex-aluna do colégio expressavam isso. Se, por um lado, eu os(as) observava na intenção de uma análise sobre as relações traçadas no contexto escolar, por outro, eles(as) me observavam e testavam, tentando compreender quem eu era e o que pretendia ali.

A turma B, por sua vez, era extremamente silenciosa, ainda que apresentasse a mesma quantidade de estudantes que a turma A. Nos dias em que as aulas entre um grupo e outro eram seguidas, o contraste em relação às conversas em sala era significativo. Contudo, o silêncio não simbolizava atenção aos conteúdos de sociologia, ao menos não de modo proferido. Na verdade, como pude observar, era o inverso: na maior parte do tempo, os(as) estudantes estavam concentrados(as) em atividades de outra disciplina ou em qualquer outro exercício, o que justificava o silêncio mantido.

Em momentos a sós, Lúcia declarava o desânimo ao ministrar aulas à turma $\mathrm{B}$, uma vez que não recebia nenhum retorno em relação às suas exposições e à dinâmica em sala. Os(as) discentes falavam muito pouco e, quando o faziam, era em resposta a alguma questão que lhes era direcionada. Isso, segundo a própria Lúcia, dificultava o discernimento acerca do grau de entendimento e assimilação sobre o conteúdo trabalhado. Se na turma $\mathrm{A}$ a figura de estagiária foi bem recebida, sendo solicitada a qualquer dúvida ou questionamento, na $\mathrm{B}$ minha presença passava quase despercebida; não havia interesse ou curiosidade pela função que desempenhava, muito menos existia preferência pelas minhas explicações, prevalecendo total imparcialidade. A despeito disso, foi durante uma aula ministrada nessa turma que presenciei uma das situações que mais me chamou atenção durante o estágio-etnografia.

O episódio em questão ocorreu em um dia de avaliação dos(as) alunos(as). Como sugere o protocolo interno da escola, entramos na sala, solicitamos que a turma guardasse o material e deixasse sobre a mesa somente o essencial para a realização da prova. Desta feita, entregamos as avaliações, pedimos silêncio e observamos a turma sentadas de frente para a turma, na mesa de Lúcia. As avaliações eram aplicadas durante uma aula apenas. Quando ocorriam aulas conjugadas, na primeira parte 
fazíamos revisão do conteúdo abordado na prova para, na seguinte, aplicá-la, o que não era o caso naquele momento.

Alguns minutos antes do término da aula, acometida pelo estresse de não conseguir concluir sua avaliação no prazo estipulado, uma aluna levantou-se da carteira aos prantos, queixando-se de sua incapacidade em realizar a prova e demonstrando estar sob excessiva pressão. Perplexos com a situação, eu e o restante da turma apenas acompanhamos a tentativa sem sucesso de Lúcia em acalmar a aluna. Depois de algum tempo, um dos estudantes se dispôs a ir à sala ao lado para comunicar o namorado da aluna sobre o que estava acontecendo. Na percepção desse colega, o namorado estava habituado com situações semelhantes e rapidamente chegou, conseguindo acalmar a garota, enquanto a levava para a área externa à sala de aula. Após a saída da aluna e seu namorado, a avaliação prosseguiu como se nada houvesse ocorrido.

Esse episódio proporcionou diversas reflexões, mas foi principalmente durante os momentos de escrita do diário de campo-estágio que me senti capaz de tecer uma análise mais consistente sobre os muitos significados que aquela situação poderia apresentar. $\mathrm{O}$ mais importante, talvez, esteja alinhado à percepção de que as escolas não estão suficientemente preparadas para lidar com pessoas que extrapolam aquilo que François Dubet (1997) denominou como "aluno médio". Conforme ensina esse conceito, todos aqueles e aquelas que não se enquadram na ideia desincorporada, genérica e individualizada de estudante convertem-se em um problema para o funcionamento "normal" das instituições de ensino.

Em casos como estes, é possível perceber como a rotina escolar tende a tratar qualquer perturbação em sua ordem como um "problema" que precisa ser rapidamente solucionado. Desse modo, expressões, relacionamentos, comportamentos, saberes ou perspectivas que representem algum risco ou diferença em relação ao funcionamento da cultura escolar dominante são desencorajados, em nome da manutenção de uma identidade fictícia, representada pela ideia do "aluno médio" que somente existe no e para o sistema escolar. Ainda assim, situações como a citada acima não constituem um evento esporádico no cotidiano de trabalho docente. Todos os dias acontecem "coisas" nas escolas, que obrigam profissionais de ensino a tomar atitudes para as quais nem sempre estão preparados ou preparadas.

O processo de escrever sobre esse episódio possibilitou a produção de uma consciência crítica (Strathern, 1987) acerca da minha posição enquanto estagiária-etnógrafa e, sobretudo, como professora em formação. Ao colocar em diálogo os conhecimentos apreendidos por meio da teoria antropológica com a experiência vivenciada no campo-estágio, pude compreender que a necessidade de desenvolvimento de uma sensibilidade docente que consiga lidar com a composição da diferença em sala de aula - isto é, lidar com tudo aquilo que foge à noção de aluno médio - perpassa necessariamente as noções de estranhamento e desnaturalização das estruturas e da organização escolar.

O processo formativo usualmente planejado para o estágio insere acadêmicos e acadêmicas das mais variadas licenciaturas em um jogo de semelhanças e diferenças que marcam sua experiência formativa enquanto ambígua (Silva, Hall \& Woodward, 2014). A adesão da prática etnográfica, a partir da observação participante e da escrita, ao processo formativo do estágio contribui para a produção de uma maior reflexividade acerca das posições colocadas em jogo nessa vivência, bem como da própria 
noção de professoralidade a ser assumida pelo estagiário(a). O estágio-etnografia educa e forma o(a) licenciando(a) na medida em que o desloca do interior das categorias já fixadas como "naturais" dentro da escola, articulando teoria e prática, ao assumir atividades que ultrapassem a mera observação passiva das aulas e incorporem a problematização de práticas pedagógicas consideradas próprias à docência, em diálogo com as múltiplas dinâmicas que constituem uma instituição de ensino.

Conforme mostram Brum e Jesus (2018), a aprendizagem humana pode ser compreendida pelas habilidades, sensibilidades e orientações que são valorizadas e estimuladas em um ambiente particular. No caso das escolas, são os conhecimentos científicos que organizam os tempos, os ritmos e disciplinam os próprios corpos de docentes e discentes. O que não significa que outros conhecimentos deixem de participar da vida escolar, principalmente se considerarmos que cada estabelecimento de ensino se compõe a partir de vários subambientes, que apresentam outras formas de socialidade, relações e saberes, as quais não estão totalmente atreladas às dinâmicas planejadas por cada instituição.

O trabalho etnográfico certamente não nos auxiliará a restaurar qualquer normalidade escolar, posto esta ser uma ideação, mas talvez represente uma maneira de desenvolver em nós disposições e sensibilidades que nos habilitem a conviver melhor com as diferenças próprias ao mundo vivido. Como expôs Calavia Sáez (2013), entre outros autores(as), o objetivo da antropologia, enquanto disciplina científica, é ampliar a compreensão do humano. O que implica em incorporar outras perspectivas de mundo, além das que já nutrimos dentro da limitada cosmovisão ocidental que chamamos de discurso humano. De fato, isso é o que tem feito a antropologia ao lidar com as "linguagens estranhas" (Clastres, 1968 apud Goldman, 2011) de pessoas que intitulamos como "nativos". Desse modo, o propósito de meu projeto se define por uma concepção da etnografia enquanto exercício de formação docente que habilita a visualização e, consequentemente, a compreensão de outras perspectivas dentro da escola.

\section{Por um estágio-etnografia nas escolas: considerações finais}

Ao longo do presente texto, apresentamos algumas reflexões sobre as vantagens de um estágio-etnografia nas escolas. Baseando-nos, principalmente, nos benefícios que a antropologia pode proporcionar ao ensino de sociologia, propomos uma articulação entre teoria e realidade de vida, tendo como mediação a diferença. A antropologia adentra esse contexto por permitir um diálogo entre ambos, a partir de uma perspectiva que considere os diversos tipos de conhecimentos existentes no campo escolar (Brum \& Jesus, 2018).

Isso significa dizer que um estágio-etnografia nas escolas possibilita ao licenciando ou licencianda a fabricação de práticas pedagógicas que concebam a diferença para algo além de um tema-objeto, que visa a aliviar tensões ocasionadas por discriminações e preconceitos em sala de aula. Em outras palavras, é necessário produzir práticas pedagógicas que concebam a diferença enquanto uma matéria viva presente no ambiente escolar e que emerge dos sujeitos e das relações que ali são estabelecidas, agindo sobre e sob os regimes de conhecimento, alterando e ampliando as perspectivas limitadas do sistema escolar. 
O estágio compreende um período liminar, cujo objetivo se estende desde a experimentação da futura atuação profissional de licenciandos e licenciandas até a preparação para os momentos mais adversos vivenciados em sala de aula. Sendo assim, essa prática por si só se torna um exercício de estranhamento e desnaturalização. Primeiro, por colocar estagiários e estagiárias diante uma posição desconhecida no campo escolar, provocando certo incômodo, tanto pela indefinição contida na função a ser desempenhada, quanto pela ausência de certeza acerca da postura a ser assumida diante das turmas, docentes e demais agentes institucionais.

Mas o estágio também proporciona um movimento simultâneo de retorno e de deslocamento em relação a espaços para os quais já se possui alguma familiaridade. A desnaturalização de aluno ou de aluna, única posição escolar vivenciada até então pelos estagiários e estagiárias, exige o estranhamento de sua própria condição de aprendiz; isto é, exige deles(as) que se coloquem para além da função de observar e "absorver" os conteúdos didáticos, afigurando-se como alguém que transmite os conteúdos esperados. No âmbito das Ciências Sociais, o exercício do estranhamento está relacionado ao ato de desconfiar. A desconfiança em torno dos temas familiares que constituem os objetos de estudo da disciplina se estende também às bases teóricas e aos princípios de análise da própria Sociologia (Carniel \& Bueno, 2018).

Diante dessa experiência cultural provocada pelos estágios supervisionados, aprendizes das mais diversas disciplinas vivenciam um período de indefinições que, ao longo do tempo, se transformam em elementos imprescindíveis para a formação no magistério, pois é exatamente nos momentos liminares e dúbios que a emergência de um "espírito docente" se torna necessário e a reversão dos papéis sociais de professor e de aluno se apresenta como um mecanismo essencial para a formação profissional. Entre dúvidas e inseguranças, o período liminar do estágio fomenta a construção de um ethos docente, que vislumbra na relação entre professores(as) e discentes os princípios necessários para a incorporação de um novo lugar social. Em suma, o estágio se define como a oportunidade de licenciandos e licenciandas experimentarem a alternância das posições sociais no cenário escolar e assim, quem sabe, poderem construir sua professoralidade com mais segurança e conforto.

A etnografia requer o estranhamento de fenômenos diários. Desse modo, pode-se dizer que o exercício etnográfico nas escolas incorpora a desnaturalização, pois implica em uma atitude que nos faz indagar sobre aquilo que nos é apresentado como imutável, necessário ou universal, para compreendemos as dinâmicas históricas, contingentes e parciais que possibilitaram a sua postulação. Evidentemente, uma escola continuará sendo uma instituição formadora quando analisada pela perspectiva antropológica. Contudo, o que a etnografia permite é a apreensão de relações, sujeitos, perspectivas e concepções que também participam da formação humana, mas muitas vezes são desconsideradas pelas narrativas oficiais ou institucionais que orientam a formação docente. No caso dos estágios supervisionados, a prática etnográfica favorece ainda o estabelecimento de outras alteridades que, ao invés de reduzirem o aprendizado da docência, multiplicam suas possibilidades.

É certo que a etnografia, por si só, não é capaz de alterar os tipos de relações formadas no contexto da escola. Contudo, gostaríamos de argumentar que a sua prática tende a ampliar a imaginação na formação docente, permitindo a emergência de outras maneiras de se relacionar com as instituições de 
ensino e a sua organização. Sabemos que o momento dos estágios configura uma dimensão valorizada da formação profissional, ao mesmo tempo que envolve riscos eminentes para quem se candidata ao magistério. Os efeitos dessa experiência podem influenciar negativa ou positivamente as perspectivas estudantis a respeito da docência.

Nesse contexto, a etnografia, além de expandir as funções e potências do estágio, pode tornar a inserção na escola mais interessante e produtiva para os estagiários e estagiárias, tendo em vista que seus usos favorecem articulações possíveis entre os saberes acadêmicos e as práticas de ensino (Carniel \& Rapchan, 2018). Logo, seus impactos na formação discente não se limitam ao campo do estágio, pois fixam em práxis diversas os conhecimentos científicos obtidos ao longo das formações disciplinares oferecidas pelas licenciaturas.

Nessa instância, o estágio-etnografia pode não apenas auxiliar na fabricação dessas práticas, mas também motivar os sujeitos envoltos em campo a lidarem com a diferença de modo a considerarem-na um elemento comum no ambiente escolar, o que, de fato, ela é, a despeito das dificuldades em assimilarem-na. É durante as conversas paralelas que os alunos e alunas têm durante as aulas que muitos de seus gostos e relações pessoais do dia a dia extraescolar se tornam visíveis a professores(as) e, sobretudo, à(o) estagiária(o)-etnógrafa(o).

Observar as interações dos alunos e alunas para além das limitações que a escola os impõe, isto é, observá-los enquanto sujeitos e sujeitas implica a concepção de que toda a mediação de saberes e conhecimentos ministrados em sala de aula transpassa a experiência de vida de pessoas que, por sua vez, são atravessadas pela diferença. Reconhecer isso pode não ser o grande feito para uma educação libertadora, mas com certeza é um importante passo para a construção de um sistema escolar que forneça regimes de conhecimentos menos excludentes e mais inclinados a lidarem com a diferença como algo a ser tateado em sala de aula e não sumariamente ignorado.

Fagner Carniel é Doutor em Sociologia Politica pela Universidade Federal de Santa Catarina (UFSC) e Professor Associado da Universidade Estadual de Maringá (UEM).

Daniara Thomazé Licenciada em Ciências Sociais pela Universidade Estadual de Maringá (UEM), mestranda em Antropologia e Arqueologia pela Universidade Federal do Paraná (UFPR). Bolsista da Coordenação de Aperfeiçoamento de Pessoal de Nivel Superior (Capes).

\section{REFERÊNCIAS}

Araújo, O. (2019). Estágio Supervisionado, profissionalização e profissionalidade docente: do que estamos falando? Revista Teias, 20(58), 250-264. https://doi.org/10.12957/teias.2019.39115 
Brasil. Ministério da Educação. (2006). Orientações Curriculares para o Ensino Médio - Ciências Humanas e suas tecnologias. Brasília.

Brum, C. K., \& Jesus, S. C. de. (2018). Antropologia como educação: um diálogo sobre experiências de ensino da antropologia em cursos de formação de professores e seus desafios. Ciências Sociais Unisinos. 54(2), 217-228. https://doi.org/10.4013/csu.2018.54.2.09

Carniel, F. (2013) A invenção (pedagógica) da surdez: sobre a gestão estatal da educação especial na primeira década do século XXI (Tese de Doutorado). Centro de Filosofia e Ciências Humanas, Universidade Federal de Santa Catarina, Florianópolis.

Carniel. F. (2018). Agenciar palavras, fabricar sujeitos: sentidos da educação inclusiva no Paraná. Horizontes Antropológicos, 24(50), 83-116. https://doi.org/10.1590/S0104-71832018000100004

Carniel, F., \& Bueno, Z. (2018). Aprendendo a pensar perigosamente: experiências com o PIBID de Ciências Sociais da UEM. In J. A. Martins, \& M. H. Y. Zappone (orgs). Formação Docente: percursos e reflexões a partir do PIBID-UEM (pp. 33 - 50). Maringá: EDUEM.

Carniel, F., \& Rapchan, E. S. (2018). Usos (sem abuso) do texto etnográfico em sala de aula. Revista Brasileira de Estudos Pedagógicos, 99(253), 687-699. https://doi.org/10.24109/2176-6681.rbep.99i 252.3758

Dubet, F. (1997). Quando o sociólogo quer saber o que é ser professor. Entrevista concedida a A. T. Peralva e M. P. Sposito; tradução de I. R. Bueno. Revista Brasileira de Educação, 5, 222-231.

Estrela, M. T. (Org.). (1997). Viver e construir a profissão docente. Porto: Porto Editora.

Favret-Saada, J. (1990). Être Affecté. Revue d'Histoire et d'Archives de l'Anthropologie, 8, 3-9. https:// www.persee.fr/doc/gradh_0764-8928_1990_num_8_1_1340

Fians, G. (2015). Por uma antropologia de varanda reversa: etnografando um encontro entre índios e crianças em uma escola no Rio de Janeiro. Cadernos de Campo, 24, 202-222. https://doi. org/10.11606/issn.2316-9133.v24i24p202-222

Fonseca, C. (1999). Quando cada caso NÃO é um caso: pesquisa etnográfica e educação. Revista Brasileira de Educação, 10, 58-78.

Foucault, M. (1994). Vigiar e punir: nascimento da prisão. Petrópolis: Editora Vozes.

Gusmão, N. (1997). Antropologia e educação: origens de um diálogo. Cadernos Cedes, (18)43, 8-25. https://doi.org/10.1590/S0101-32621997000200002 
Goldman, M. (2003). Os tambores dos mortos e os tambores dos vivos: Etnografia, Antropologia e Política em Ilhéus, Bahia. Revista Antropologia, 46(2), 423-444. https://doi.org/10.1590/S003477012003000200012

hooks, b. (2013). Ensinando a transgredir: a educação como prática da liberdade. São Paulo: Editora WMF Martins Fontes.

Ingold, T. (2010). Da transmissão de representações à educação da atenção. Educação, 33(1), 6-25. https://revistaseletronicas.pucrs.br/ojs/index.php/faced/article/view/6777

Ingold, T. (2016). Chega de etnografia! A educação da atenção como propósito da antropologia. Educação, 39(3), 405-411. https://doi.org/10.15448/1981-2582.2016.3.21690

Nóvoa, A. S. da. (org.). (1992). Vidas de professores. Porto: Ed. Porto.

Oliveira, A. (2017). Uma antropologia fora do lugar? Um olhar sobre os antropólogos na educação. Horizontes Antropológicos, (23)49, 233-253. https://doi.org/10.1590/s0104-71832017000300009

Oliveira, A., \& Barbosa, V. S. L. (2013). Formação de professores em ciências sociais: desafios e possibilidades a partir do estágio e do PIBID. Revista Inter-Legere, 1(13), 140-162. https://periodicos. ufrn.br/interlegere/article/view/4169

Oliveira, R. C. de. (1996). O trabalho do Antropólogo: olhar, ouvir, escrever. Revista de Antropologia, 39(1), 13-37. https://doi.org/10.11606/2179-0892.ra.1996.111579

Passeggi, M., \& Silva, V. (orgs.). (2010). Invenções de vidas, compreensão de itinerários e alternativas de formação. Natal: EDUFRN; São Paulo: Paulus.

Peirano, M. (2008). Etnografia, ou teoria vivida. Ponto Urbe, 2, 1-10. https://doi.org/10.4000/pontourbe. 1890

Pereira, A. B. (2016). A “maior zoeira" na escola: experiências juvenis na periferia de São Paulo. São Paulo: Editora da Unifesp.

Pereira, A. B. (2017). Do controverso "chão da escola" às controvérsias da etnografia: aproximações entre antropologia e educação. Horizontes Antropológicos, (23)49, 149-176. https://doi.org/10.1590/ s0104-71832017000300006

Pinho, O. (2018). Etnografia e Emancipação: Desafios Antropológicos na Escola Pública. In J. Bernardino-Costa, N. Maldonado-Torres, \& R. Grosfoguel (orgs.). Decolonialidade epensamento afrodiaspórico (pp. 341 - 360). Belo Horizonte: Autêntica Editora.

Rapchan, E., \& Carniel, F. (2016) Natureza ou cultura na formação escolar brasileira. Revista Inter-Legere, (1)18, 76-94. https://periodicos.ufrn.br/interlegere/article/view/10815 
Rocha, G. (2012). Aprendendo com o outro: Margaret Mead e o papel da educação na organização da cultura. In T. Dauster, S. Tosta, \& G. Rocha (orgs.). Etnografia e educação: culturas escolares, formação e sociabilidades infantis e juvenis (pp. 41-68). Rio de Janeiro: Lamparina.

Rodriguez, C. (2001). Black feminist anthropology: theory, politics, and poetics. New Jersey: Rutgers University Press.

Romaña, T., \& Gros, B. (2003). La profesión del docente universitário del siglo XXI: cambios superficiales o profundos? Revista de Enseñanza Universitária, 21, 7-35. https://idus.us.es/handle/11441/54876

Sáez, O. C. (2013). Esse obscuro objeto de pesquisa. Ilha de Santa Catarina: Edição do autor.

Strathern, M. (1987). The Limits of Auto-Anthropology. In A. Jackson (org.). Anthropology at Home (pp. 17-37). London: Tavistock.

Silva, T. T. et al. (2014). Identidade e diferença: a perspectiva dos estudos culturais. Petrópolis: Vozes.

Tardif, M. (2002). Saberes docentes e formação profissional. Petrópolis: Vozes.

Wagner, R. (2010). A invenção da cultura. São Paulo: Cosac \& Naify. 


\title{
QUANDO O CAMPO É O ESTÁGIO: ETNOGRAFIA E FORMAÇÃo DOCENTE
}

Resumo: O que a prática etnográfica teria a oferecer para a formação docente? Por meio de um exercício etnográfico realizado em uma instituição pública de ensino no Paraná, procuramos debater ao longo deste artigo aspectos significativos da dimensão formacional da etnografia. $\mathrm{O}$ trabalho de campo baseia-se em uma experiência de estágio docente, realizado ao longo do ano de 2018, com duas turmas de Ensino Médio de uma escola pública da região metropolitana de Maringá. A intenção é argumentar que a prática etnográfica, enquanto um exercício pedagógico a ser realizado durante o estágio supervisionado, comporta o potencial de educar a percepção dos futuros(as) professores e professoras a respeito da realidade escolar. Ao final, o texto propõe uma composição entre o campo e a literatura especializada, para dialogar com desafios éticos, políticos e formativos relacionados ao desenvolvimento de estratégias pedagógicas sensíveis às diferenças e desigualdades, que constituem as relações sociais em sala de aula.

Palavras-chave: Antropologia da educação; estágio supervisionado; etnografia escolar; formação docente; licenciatura.

\section{WHEN THE FIELDWORK IS THE TRAINING: ETHNOGRAPHY AND TEACHER EDUCATION}

\begin{abstract}
What would ethnographic practice have to offer for teacher training? Through an ethnographic exercise carried out at a school in Paraná State, Brazil, the article discusses significant aspects of the formative dimension of ethnography. The fieldwork is based on a teaching internship experience, throughout 2018, in two high school classes from a public school in the metropolitan region of the municipality of Maringá. The intention is to argue that the ethnographic practice, as a pedagogical exercise to be performed during the teacher training practice, holds the potential to educate the perception of future teachers. The text proposes a composition between the fieldwork and the specialized literature to reflect on the ethical, political, and training challenges related to the construction of pedagogical strategies to work with differences and inequalities present in the classroom.
\end{abstract}

Keywords: Educational anthropology; Initial teacher education; Schooling ethnography; Teachers' formation; Undergraduate teaching courses.

RECEBIDO: $17 / 04 / 2020$

ACEITO: 09/08/2021 